\title{
STRATEGI PENGEMBANGAN AGRIBISNIS KOPI ROBUSTA PRODUKSI KSU KETAKASI SIDOMULYO KABUPATEN JEMBER
}

\author{
Mohammad Edwinsyah Yanuan Putra ${ }^{1 *}$, Dian Galuh Pratita ${ }^{2 *}$ \\ Department of Agribusiness Management, Politeknik Negeri Jember 68101 \\ Department of Agricultural Production, Politeknik Negeri Jember 68101 \\ $\underline{\text { mohammadedwinsyah@gmail.com }}^{{ }^{*}}$, dian.gp@ $\underline{\text { polije.ac.id }}^{2^{*}}$
}

\begin{abstract}
This research is based from the decline in quantity of coffee robusta Jember production, This mainly because of production level and quality was lower compared with the others area that also produce robusta coffea as their commodity. The research is aims to review the priorities in the development strategy agribusiness robusta coffee jember production. Research methods that were used is SWOT and AHP with data retrieval from KSU Ketakasi Sidomulyo use interview methods to respondents. SWOT methods generate priority strategy the combination of strength and opportunity with weights 3,628 , and the priority strategy is increase productivity and integrated agribusiness development. The AHP methods generate priority strategy in this research at the level of criteria is optimistic with weight 0,705 , at the level of target is improve the performance on farm sector with weight 0,469 , and the strategy that is used is increase productivity with weight 0,269 .
\end{abstract}

Keywords: development, agribusiness, robusta coffee, SWOT, AHP

\begin{abstract}
Abstrak
Penelitian ini didasari dari menurunnya kuantitas kopi robusta produksi Kabupaten Jember, hal tersebut utamanya disebabkan tingkat produksi dan kualitas yang cenderung lebih rendah jika dibandingkan dengan wilayah lain yang juga memproduksi komoditi kopi. Penelitian bertujuan untuk mengetahui prioritas strategi dalam pengembangan agribisnis kopi robusta produksi Jember. Metode penelitian yang digunakan adalah SWOT dan AHP dengan pengambilan data pada KSU Ketakasi Sidomulyo dengan menggunakan metode wawancara kepada responden. Metode SWOT menghasilkan prioritas strategi perpaduan antara kekuatan dan peluang dengan bobot nilai 3,628, dan prioritas strateginya adalah peningkatan produktivitas dan pengembangan agribisnis terpadu. Pada metode AHP menghasilkan prioritas strategi yang didapatkan dalam penelitian ini di level kriteria adalah optimis dengan bobot nilai 0,705 , pada level sasaran adalah meningkatkan kinerja sektor on farm dengan bobot nilai 0,469, dan strategi yang digunakan adalah meningkatkan produksi dengan bobot nilai 0,269.
\end{abstract}

Kata kunci: pengembangan, agribisnis, kopi robusta, SWOT, AHP.

\section{Pendahuluan}

Sektor perkebunan Indonesia tengah dipacu menghasilkan produk bermutu, diantaranya kopi robusta yang berprospek baik. Ekspor kopi robusta Indonesia sepuluh tahun mendatang memiliki prospek yang baik. Namun Indonesia memiliki daya saing ekspor kopi terendah dibandingkan Brazil, Kolombia dan Vietnam (Suprayogi, B.M., 2017).

Elisha (2015) menganalisis harga kopi dunia terhadap volume ekspor kopi Indonesia ke Amerika Serikat dalam jangka pendek dan jangka panjang, dan menganalisis nilai tukar rupiah (kurs) terhadap volume ekspor kopi Indonesia ke Amerika Serikat dalam jangka pendek dan jangka panjang. Hasil penelitian diperoleh dari 3 variabel yaitu Produksi Kopi (X1) berpengaruh positif dan signifikan dalam jangka pendek dan jangka panjang. Harga Kopi Dunia (X2) tidak signifikan dalam jangka pendek dan jangka panjang. Nilai Tukar Rupiah (Kurs) (X3) tidak signifikan dalam jangka pendek, sedangkan dalam jangka panjang berpengaruh positif dan signifikan. Berdasarkan hasil penelitian ini disarankan petani kopi perlu meningkatkan kuantitas produksi kopi Indonesia, perlu adanya sertifikasi mutu terhadap kopi Indonesia sehingga dapat menjamin konsumen dan meningkatkan nilai jual kopi Indonesia, dengan adanya kebijakan yang tepat melalui peningkatan ekspor kopi, diharapkan ekspor Indonesia mengalami peningkatan dan menambah pendapatan nasional melalui devisa yang diperolehnya tanpa terjadi inflasi.

Widayanti (2009) mengemukakan bahwa faktor-faktor yang berpengaruh terhadap kuantitas ekspor kopi Indonesia adalah harga ekspor kopi (harga FOB), harga kopi dalam negeri nilai tukar rupiah terhadap dollar Amerika dan penawaran kopi tahun t-1. Raharjo (2013) menunjukkan bahwa PDB riil, nilai tukar rupiah terhadap dollar, harga ritel kopi negara pengimpor 
memiliki pengaruh yang positif terhadap volume permintaan ekspor kopiIndonesia

Sihotang (2013) mengemukakan bahwa produksi kopi Indonesia berpengaruh positif secara signifikan terhadap volume ekspor kopi Indonesia, dan volume ekspor kopi tersebut bersifat elastis terhadap produksi kopi di Indonesia, mengindikasikan bahwa peningkatan produksi kopi sampai batas tertentu mungkin masih akan diikuti oleh peningkatan ekspor kopi di Indonesia. Purnamasari et al (2014) mengemukakan bahwa Kolombia diikuti oleh Brazil dan Vietnam memiliki keunggulan komparatif pada semua periode. Sedangkan Indonesia masih berada pada peringkat ke empat.

Soviandre et al (2014) mengemukakan bahwa Harga Kopi Internasional, dan Nilai Tukar Rupiah terhadap US Dollar secara simultan berpengaruh signifikan terhadap Volume Ekspor Kopi dari Indonesia ke Amerika Serikat. Setiawan (2016) mengemukakan komoditas kopi yaitu Jawa Timur dan tepatnya berada bahwa kopi Indonesia di Pasar Malaysia memiliki di Kabupaten Jember. Kabupaten Jember sendiri daya saing (nilai RCA $>1$ ) namun mengalami merupakan satu-satunya yang memiliki Pusat Penelitian penurunan daya saing setelah diberlakukannya CEPT- Kopi dan Kakao, oleh karena itu kopi di Kabupaten AFTA.

Nalurita et al (2014) mengemukakan bahwa secara komparatif kopi Indonesia memiliki daya saing di pasar internasional. Berdasarkan analisis Berlian Porter, kopi Indonesia juga memiliki keunggulan secara komparatif yang didukung oleh kondisi faktor (sumberdaya alam, modal, tenaga kerja, IPTEK), industri terkait dan pendukung, peran pemerintah dan kesempatan.

Sidabalok (2017) mengemukakan bahwa Variabel nilai tukar, pendapatan nasional negara pengimpor, dan harga kopi sebagai barang substitusi teh berpengaruh positif dan siginifikan terhadap jumlah ekspor teh Indonesia ke-5 negara pengimpor teh terbesar (Rusia, Pakistan, Malaysia, Jerman, dan AS).

Sundari, S. (2015) mengemukakan bahwa untuk memperoleh produk bermutu, perusahaan-perusahaan perlu menerapkan konsep kendali mutu dan jaminan mutu. Kendali mutu mengandung arti setiap produk harus diproduksi sesuai dengan permintaan, dengan pendekatan Manajemen Mutu Terpadu yang
memaksimumkan partisipasi karyawan dan daya saing organisasi melalui perbaikan terus menerus.

Dewi et al (2015) mengemukakan bahwa hasil analisis strategi pemasaran Perusahaan Kopi Banyuatis setelah menggunakan metode BCG berada pada posisi tanda tanya (Question Mark). Dilihat dari titik perpotongan tingkat pertumbuhan pasar dan pangsa pasar relatif pada matriks $\mathrm{BCG}$, yang berarti bahwa perusahaan berada pada pasar relatif rendah akan tetapi bersaing dalam industri pertumbuhan pasar yang pesat.

Sugiharta (2016) mengemukakan bahwa identifikasi dapat memaksimalkan kekuatan (Strenghts) dan faktor internal UD Tani Sejati kekuatannya yaitu citra peluang (Oppotunnities), namun secara bersamaan perusahaan yang baik, akan tetapi kelemahannya yaitu dapat meminimalkan kelemahan (Weaknesses) dan jaringan pemasaran kurang, sedangkan pada faktor ancaman (Threats). Proses pengambilan keputusan 
strategis selalu berkaitan dengan pengembangan misi, dapat membuat antisipasi apabila ada sesuatu yang tujuan, strategi, dan kebijakan perusahaan. Demikian terjadi di luar perkiraan.

perencanaan strategis harus menganlisis faktor-faktor strategis perusahaan (kekuatan, kelemahan, peluang dan ancaman) dalam kondisis yang ada saat ini. Hal ini disebut dengan Analisis Situasi (Rangkuti, 2014).

\subsection{Analytical Hierarchy Process (AHP)}

Analytical Hierarchy Process (AHP) adalah salah satu bentuk model pengambilan keputusan yang pada dasarnya berusaha menutupi kekurangan dari model pengambilan keputusan yang lainnya. Alat utama dalam model AHP ini adalah sebuah hierarki fungsional dengan input utamanya berupa persepsi manusia. Dengan hirarki, suatu masalah yang kompleks dan tidak terukur dipecah ke dalam kelompokkelompoknya dan kemudian kelompok-kelompok tersebut diatur menjadi sebuah bentuk hirarki (Brojonegoro, 1992).

Kelebihan model AHP dibandingkan model pengambilan keputusan lainnya terletak pada kemampuan AHP untuk memecahkan masalah yang multiobjectives dan multicriterias. Hal ini disebabkan karena metode ini memiliki fleksibilitas yang tinggi, terutama dalam pembuatan hirarkinya, sehingga model AHP dapat menangkap beberapa tujuan dan beberapa Adapun beberapa metode penelitian Strategi kriteria sekaligus dalam sebuah model atau sebuah Pengembangan yang digunakan pada penelitian ini hirarki. Bahkan AHP mampu memecahkan masalah- adalah sebagai berikut; 1. Menetapkan posisi strategis masalah yang memiliki tujuan-tujuan yang berlawanan, agribisnis kopi robusta saat ini melalui penyusunan kriteria-kriteria yang berlawanan, dan tujuan serta matriks Internal - Eksternal (I-E). 2. Menggambarkan kriteria yang berlawanan dalam sebuah model. secara jelas bagaimana peluang dan ancaman eksternal Karenanya, keputusan yang diambil melalui model yang dihadapi perusahaan dapat diselesaikan dengan AHP sudah akan mempertimbangkan berbagai tujuan kekuatan dan kelemahan yang dimiliki perusahaan dan berbagai kriteria yang berbeda atau bahkan saling melalui penyusunan matriks SWOT, 3. Memilih bertentangan (Saaty, 2000).

\subsection{Analisis Sensitivitas}

Menurut Brojonegoro (1992), analisis sensitivitas dapat 3. Hasil dan Pembahasan dipakai untuk memprediksi keadaan apabila terjadi suatu perubahan yang cukup besar. Misalnya terjadi perubahan bobot prioritas atau urutan prioritas dari kriteria karena ada perubahan kebijakan. Maka pertanyaan yang muncul adalah bagaimana urutan prioritas alternatif yang baru dan tindakan apa yang perlu dilakukan.

Apabila dikaitkan dengan suatu periode waktu, maka (SDA), keadaan geografis yang mendukung, kegiatan dapat dikatakan bahwa analisis sensitivitas adalah pupuk bersubsidi, dan adanya Pusat Penelitian Kopi unsur dinamis dari sebuah hirarki. Artinya, penilaian dan Kakao Indonesia; 2. Faktor kelemahan (weakness) yang dilakukan pertama kali dipertahankan untuk suatu yang meliputi : umur tanaman kopi sudah tua, budidaya jangka waktu tertentu dan adanya perubahan kebijakan belum intensif dan produktivitas lahan masih rendah, atau tindakan, cukup dilakukan dengan analisis populasi tanaman yang kurang produktif, kualitas Kopi sesitivitas untuk melihat efek yang terjadi. Kestabilan masih rendah; 3. Faktor peluang (opportunity) yang suatu hirarki juga dapat ditentukan berdasarkan analisis meliputi : lokasi dapat dikembangkan sebagai lokasi sensitivitas. Makin besar deviasi atau perubahan percontohan, permintaan kopi terus meningkat, prioritas yang terjadi, makin tidak stabil hirarki pengelolaan hasil panen mendukung, pasar Lokal, tersebut. Sensitivitas hirarki, penting untuk Domestik, dan Internasional luas; 4. Faktor ancaman implementasi kebijakan karena pengambil keputusan (treaths) yang meliputi : sifat pasar terbuka yang 
mengakibatkan persaingan, daya saing masih rendah, Meskipun strategi SO merupakan alternatif strategi fungsi penyuluhan masih belum maksimal.

Setelah faktor-faktor internal dikelompokkan menjadi yang memiliki nilai pembobotan tertinggi, namun belum tentu semua alternatif strategi tersebut dapat kekuatan dan kelemahan, dan faktor-faktor eksternal dikelompokkan menjadi peluang dan ancaman, langkah selanjutnya adalah melakukan pembobotan IFAS EFAS dan penyusunan matriks SWOT dengan hasil yang disajikan pada tabel 1. Selanjutnya untuk hasil prioritas strategi SWOT disajikan pada tabel 2.

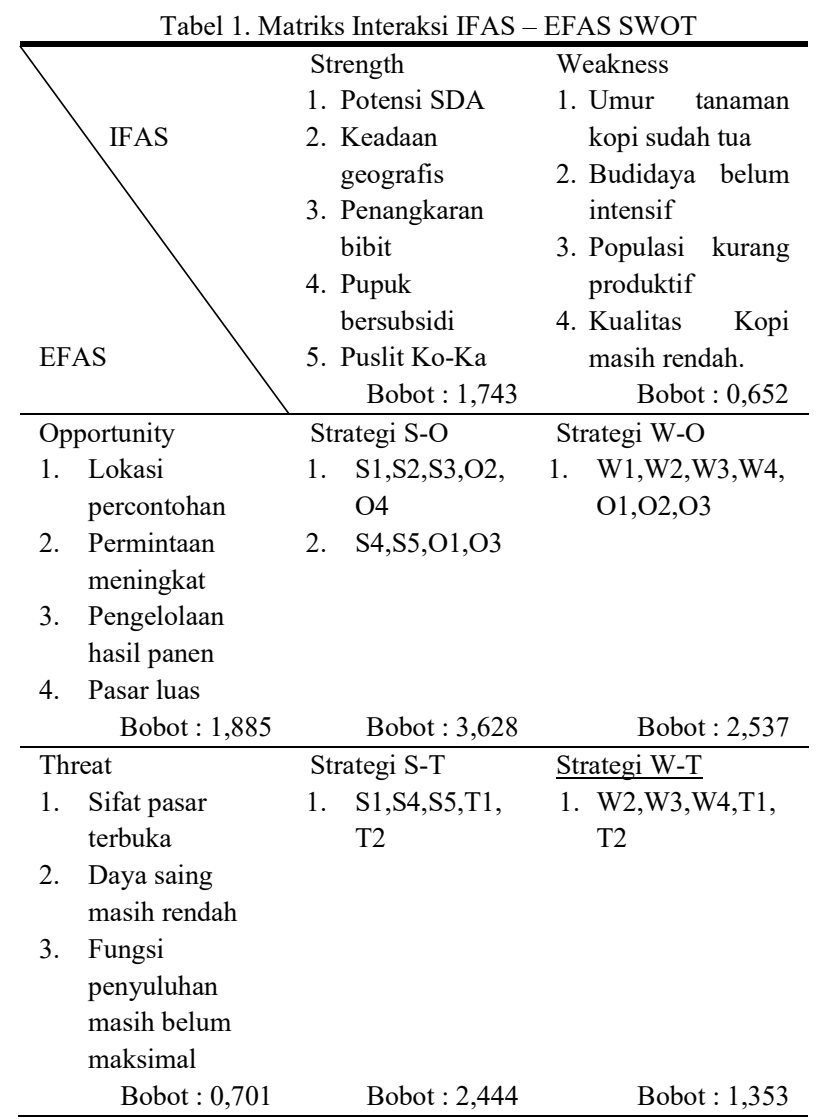

Tabel 2. Urutan Prioritas Alternatif Strategi SWOT

\begin{tabular}{ccc}
\hline Prioritas & Strategi & Bobot Nilai \\
\hline I & Strength-Opportunity (SO) & 3,628 \\
II & Weakness - Opportunity (WO) & 2,537 \\
III & Strength - Threat (ST) & 2,444 \\
IV & Weakness - Threat (WT) & 1,353 \\
\hline
\end{tabular}

dilaksanakan secara simultan. Sehingga perlu untuk dipilih kembali prioritas apabila pada saat pelaksanaanya secara bersama-sama mengalami kendala sumber daya. Penentuan prioritas strategi pengembangan agribisnis kopi robusta Kabupaten Jember pada penelitian ini selanjutnya akan dianalisa menggunakan metode Analytical Hierarchy Process (AHP).

\subsection{Penyusunan Hirarki}

Penyusunan hirarki merupakan bagian terpenting dari model AHP, karena akan menjadi dasar bagi para responden untuk memberi penilaian/pendapat secara lebih sederhana. Dengan menggunakan hirarki pada model AHP diharapkan dapat mempermudah dan menyerdahanakan permasalahan yang kompleks.

Model AHP yang digunakan dalam penelitian ini, hirarki yang disusun terdiri dari 4 tingkatan, dengan tingkat puncak sebagai goal/fokus dari hirarki, yaitu : Strategi Pengembangan Agribisnis Kopi Robusta Produksi Jember. Hirarki model AHP ini beserta nilai bobot hasil analisis menyeluruh secara lengkap disusun, dan hasil nilai berdasarkan urutan prioritas tertinggi yang akan ditampilkan pada tabel 3

Pada tingkat strategi, tidak hanya dimasukkan alternatif strategi dari strategi terpilih pada matriks SWOT yaitu alternatif strategi SO, tetapi juga disertakan seluruh alternatif strategi yang terdapat pada matriks SWOT. Hal ini dilakukan untuk melihat penilaian responden terhadap faktor lain yang dimiliki oleh Kabupaten Jember terkait dengan agribisnis kopi robusta. Penambahan alternatif strategi ini dianggap penting karena alternatif dari pilihan strategi SO hanya berfokus pada segala sesuatu yang ada diluar Kabupaten Jember, seperti peluang pasar domestik dan internasional, tanpa adanya perhatian terhadap hal mendasar pada suatu sistem agribisnis yaitu keterkaitan antar sistem dari hulu hingga ke hilir. Selain itu, berdasarkan dari hasil penilaian dalam analisis SWOT, pembobotan antar faktor terpaut tidak terlalu jauh.

Tabel 3. Hasil Prioritas Strategi dengan Metode AHP

\begin{tabular}{|c|c|c|c|}
\hline & Level & Definisi & Bobot \\
\hline Pembobotan interaksi IFAS - EFAS menghasilkan & 1 & Skenario & \\
\hline Pembobotan interaksi IFAS - EFAS menghasilkan & & 1. Optimis & 0,705 \\
\hline alternatif strategi yang mendapat bobot paling tinggi & & 2. Status Quo & 0,211 \\
\hline adalah Strength - Opportunity (SO), yang dijelaskan & & 3. Pesimis & 0,084 \\
\hline sebagai strategi menggunakan kekuatan untuk & 2 & Sasaran & \\
\hline memanfaatkan peluang/kesempatan yang ada. Kondisi & & 1. Meningkatkan Kinerja Sektor Hulu & 0,147 \\
\hline memantatkan peruang/kesempatan yang ada. Nondist & & 2. Meningkatkan Kinerja Sektor On Farm & 0,469 \\
\hline tersebut menguntungkan bagi Kabupaten Jember untuk & & 3. Meningkatkan Kinerja Sektor Hilir & 0,383 \\
\hline pengembangan Agribisnis Kopi Robusta, karena dari & 3 & Alternatif Strategi & \\
\hline sisi faktor internal, Kabupaten Jember memiliki & & 1. Meningkatkan produksi. & 0,269 \\
\hline kekuatan yang lebih tinggi dari kelemahannya, & & 2. Meningkatkan Pelatihan dan Penyuluhan. & 0,251 \\
\hline 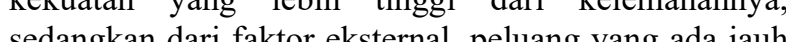 & & 3. Meningkatkan Daya Saing. & 0,144 \\
\hline sedangkan dari faktor eksternal, peluang yang ada jauh & & 4. Menerapkan Agribisnis Terpadu. & 0,144 \\
\hline lebih besar dari ancaman dalam rangka melaks & & 5.Pemanfaatan Teknologi. & 0,144 \\
\hline
\end{tabular}
pengembangan agribisnis kopi robusta. 
Dari tabel 3 tersebut dapat disimpulkan bahwa dalam Jember, 4. Menerapkan Agribisnis Terpadu dengan usaha mengembangkan agribisnis kopi robusta di memanfaatkan potensi sumber daya manusia serta Kabupaten Jember, skenario yang dianggap paling sumber daya alam untuk mengembangkan suatu sistem realistis adalah skenario Optimis, dengan sasaran yang agribisnis terpadu berbasis kopi pada setiap wilayah menjadi prioritas adalah Meningkatkan Kinerja Sektor utama penghasil kopi robusta, diantaranya dengan On Farm. Untuk mencapai sasaran tersebut prioritas adanya kerjasama antara lembaga makro dan mikro yang dapat dilakukan adalah dengan meningkatkan yang meliputi kelompok tani serta koperasi. Dengan produktivitas. Hasil strategi pengembangan agribisnis adanya kerjasama tersebut maka akan semakin kopi robusta produksi Jember menunjukkan hasil meningkatkan potensi agribisnis kopi robusta di persyaratan analisis dapat diterima dengan Overall wilayah Kabupaten Jember, 5. Pemanfaatan Teknologi Inconsistency Ratio sebesar 0,04, yang berarti bahwa untuk membangun sistem dan usaha-usaha pengolahan penilaian teruji konsisten. Saaty (2000) menyatakan kopi serta peningkatan sistem pemasaran didasarkan bahwa nilai Inconsistency Ratio $\leq 0,1$ yang berarti atas sumber daya dan orientasi pasar. Dengan keputusan yang diambil oleh responden key person perkembangan saat ini yang sarat dengan era teknologi dalam menentukan skala prioritas dapat diterima. digital sangat berdampak pada segala aspek usaha Semakin kecil nilai Inconsistency Ratio maka semakin termasuk pada sistem pemasaran. Pemanfaatan konsisten responden dalam menentukan skala prioritas. teknologi dalam rangka membangun sistem usaha dan

\subsection{Strategi Pengembangan Agribisnis}

pemasaran akan memberikan pengaruh positif pada peningkatan pangsa pasar.

Peningkatan kinerja pada sektor On Farm, menurut hasil penilaian para responden merupakan sasaran yang harus menjadi prioritas utama bagi Kabupaten Jember. Analisis sensitivitas ini dilakukan untuk melihat Hal ini sesuai dengan realita bahwa kondisi budidaya sensitivitas dari prioritas yang telah didapatkan apabila kopi robusta Kabupaten Jember masih belum mampu ada sedikit perubahan pada penilaian. Selain itu, analisa menghasilkan tingkat produksi sesuai dengan harapan ini juga dapat digunakan untuk meramalkan keadaan yang seharusnya seperti kondisi agribisnis di negara- seandainya terjadi perubahan yang signifikan. Sebagai negara lain pesaing produsen kopi robusta. Berdasarkan contoh perubahan bobot atau terjadi perubahan prioritas pengolahan data menggunakan metode AHP, untuk karena adanya perubahan kondisi nasional maupun mencapai sasaran peningkatan kinerja sektor on farm internasional. Yang menjadi harapan adalah prioritas telah didapatkan prioritas strategi pengembangan yang tidak terlalu berfluktuasi apabila terjadi sedikit agribisnis secara berurutan sebagai berikut ; 1. perubahan pada pembobotan.

Meningkatkan produksi dengan memaksimalkan modal dasar atau potensi yang ada di Kabupaten Jember untuk peningkatan produktivitas kopi robusta. Modal dasar yang dimiliki yaitu kondisi geografis yang mendukung, kualitas dan kuantitas sumber daya yang mencukupi, serta sarana dan prasarana yang telah tersedia. Memanfaatkan lembaga-lembaga terkait dengan sistem agribisnis kopi robusta untuk mendukung tercapainya rencana dalam rangka meningkatkan produktivitas, 2 . Meningkatkan Pelatihan dan Penyuluhan untuk memberikan edukasi dan informasi mengenai perbaikan sistem budidaya tanaman kopi robusta, diantaranya melalui pemberian klon unggul untuk perbaikan populasi tanaman. Selain itu juga dengan memberikan pelatihan terhadap tenaga ahli dan kelompon tani terkait cara budidaya hingga pengolahan agar dapat menghasilkan produk kopi dengan kualitas dan kuantitas tinggi, 3. Meningkatkan Daya Saing dengan membangun sistem dan usaha-usaha pengolahan kopi yang lebih mengarah pada upaya meningkatkan daya saing melalui pembinaan maupun penyuluhan terkait perbaikan mutu dan tampilan produk kopi olahan.

Apabila hasil penilaian dari para responden memilih pada skenario Status Quo yang menjadi prioritas paling realistis, maka terjadi perubahan pada sasaran dan juga pada alternatif strateginya. Dengan skenario Status Quo yang artinya kondisi lingkungan sama dengan kondisi saat ini, maka sasaran yang menjadi prioritas adalah Meningkatkan Kinerja Sektor Hilir, dengan prioritas utama strategi yang harus dilakukan Kabupaten Jember adalah Meningkatkan Daya Saing. Kabupaten Jember memiliki sarana dan prasarana yang bisa mendukung untuk menciptakan kopi olahan yang bisa bersaing dengan produk lain, sumber daya manusia yang berkompeten pun dirasa cukup untuk mengatasi permasalahan pada sektor daya saing. Agar dapat menghasilkan produk dengan kualitas tinggi maka perlu untuk menerapkan konsep Quality Control (Iskandar, 2018). Perlu dukungan dari semua pihak untuk membentuk suatu unit pengolahan kopi berkualitas sehingga bisa menciptakan suatu produk yang identik dengan Kabupaten Jember dan memiliki daya saing di pasar.

Sehingga Kabupaten Jember bisa menghasilkan produk Apabila seluruh responden memilih skenario Pesimis bersaing dengan kualitas yang mampu bersaing pada sebagai skenario yang paling realistis, maka akan pasar. Selain itu dengan adanya penyuluhan ataupun terjadi perubahan juga pada sasaran serta prioritas pelatihan maka akan turut meningkatkan Sumber Daya alternatif strategi. Skenario Pesimis, yang artinya Manusia yang dapat menjadi pendukung dalam kondisi lingkungan lebih buruk dari kondisi saat ini. peningkatan mutu olahan kopi robusta di Kabupaten Maka sasaran yang menjadi prioritas adalah 
Meningkatkan Kinerja Sektor Hulu dengan prioritas Sehingga dapat meningkatkan produktivitas komoditas alternatif strategi yang harus dilakukan oleh Kabupaten kopi di Kabupaten Jember. Upaya yang dapat Jember adalah Pelatihan. Dengan kondisi yang kurang dilakukan adalah dengan memaksimalkan potensi mendukung maka peningkatan kinerja sektor hulu wilayah yang dapat dikembangkan sebagai lahan adalah yang paling penting untuk diperhatikan. budidaya komoditas kopi, karena dari segi geografis Meningkatkan kinerja sektor hulu merupakan hal pun Kabupaten Jember sangat layak untuk syarat mutlak yang harus dilakukan dalam pengembangan tumbuh dari komoditas kopi robusta. Disamping itu sistem agribisnis. Bentuk peningkatan kinerja sektor juga perlu untuk dilakukan penyelenggaraan agribisnis hulu dapat dijelaskan sebagai pelatihan dan penyuluhan terpadu untuk lebih mengembangkan potensi petani budidaya hingga pengolahan, perbaikan sarana bibit, kopi rakyat yang juga memiliki sumbangsih tinggi pada industri pupuk, sarana dan prasarana budidaya.

Berdasarkan hasil perbandingan diatas, dapat disimpulkan bahwa hirarki yang dibentuk dalam upaya pengembangan agribisnis kopi robusta produksi Jember merupakan hirarki yang tidak stabil. Hal ini ditunjukkan dengan terjadinya perubahan apabila skenario yang diprioritaskan berbeda. Namun hal ini dapat diterima karena dalam pengembangan agribisnis sangat dipengaruhi oleh banyak faktor, tidak hanya faktor dari salah satu sektor namun dari keterpaduan antara sektor dalam sistem agribisnis, baik faktor intern maupun faktor eksternal yang tentu saja tidak dapat dikontrol dapat mempengaruhi suatu sistem agribisnis. Hal tersebut berarti bahwa apabila terjadi perubahan yang signifikan, maka akan terjadi perubahan pula pada sasaran pengembangan agribisnis sekaligus alternatif strategi yang akan dilakukan pun akan mengalami perubahan. Dengan memahami ketidakstabilan hirarki tersebut dalam penentuan prioritas strategi pengembangan agribisnis, maka Kabupaten Jember dapat membuat antisipasi apabila terjadi sesuatu yang diluar perkiraan.

\section{Kesimpulan}

Prioritas strategi pengembangan agribisnis kopi robusta produksi Jember adalah dengan menggunakan scenario optimis dan untuk sasaran yang harus dicapai secara berurutan adalah ; meningkatkan produksi, menyelenggarakan pelatihan dan penyuluhan, peningkatan daya saing, menjalankan program agribisnis terpadu, dan pemanfaatan teknologi.

Prioritas strategi ini sangat mungkin untuk terjadi perubahan, utamanya apabila terjadi hal yang diluar rencana. Apabila skenario yang dianggap paling realistis adalah status quo maka sasaran yang harus dicapai adalah meningkatkan kinerja sektor hilir dan prioritas strategi yang digunakan adalah meningkatkan daya saing. Sedangkan apabila skenario yang dianggap paling realistis adalah pesimis maka sasaran yang harus dicapai adalah meningkatkan kinerja sektor hulu dengan strategi yang harus dilakukan adalah menyelenggarakan pelatihan dan penyuluhan.

Saran yang bisa disampaikan dalam penelitian ini adalah Kabupaten Jember harus membuat prioritas pengembangan agribisnis kopi robusta dengan lebih mengutamakan pada peningkatan produktivitas lahan. peningkatan produktivitas bagi Kabupaten Jember. Selain itu juga dilakukan upaya pembinaan serta penyuluhan dari sektor hulu hingga hilir agar selain meningkatkan produksi juga meningkatkan pendapatan bagi petani rakyat.

Saran yang dapat disampaikan oleh penulis untuk penelitian selanjutnya adalah dengan penambahan responden yang lebih variatif, misalnya dengan penambahan lokasi penelitian serta melibatkan semua lini sektor agribisnis kopi robusta.

Dalam kesimpulan tidak boleh ada referensi. Kesimpulan berisi fakta yang didapatkan, cukup menjawab permasalahan atau tujuan penelitian (jangan merupakan pembahasan lagi); Nyatakan kemungkinan aplikasi, implikasi dan spekulasi yang sesuai. Jika diperlukan, berikan saran untuk penelitian selanjutnya. Nyatakan simpulan dalam kalimat berbentuk paragraf, bukan dalam bentuk numbering.

\section{Daftar Rujukan}

[1] C. Hamedeko, Dwiny Meidelfi, and Aldo Erianda, "Sistem Monitoring Rental Mobil Berbasis Android Menggunakan GPS", JACOST, vol. 1, no. 2, pp. 56 - 60, Dec. 2020.

[2] F. Astiko and Achmad Khodar, "The Sentiment Analysis Reviewing Indosat Services from Twitter Using the Naive Bayes Classifier", JACOST, vol. 1, no. 2, pp. 61 - 66, Dec. 2020.

[3] I. P. Sari and Al Amin, "Sistem Pendukung Keputusan Seleksi Penyiaran Berita Menggunakan Metode Profile Matching", JACOST, vol. 1, no. 2, pp. 67 - 73, Dec. 2020.

[4] Asosiasi Eksportir Kopi Indonesia. (2017). Luas areal dan Produksi Kopi [online]. Available http://www.aekiaice.org/page/areal-dan-produksi/id.

[5] Brojonegoro, Bambang, AHP (the Analytical Hierarchy Process). Jakarta : Pusat Antar University - Studi Ekonomi Universitas Indonesia, 1992.

[6] Bungin, Burhan, Analisis Data Penelitian Kualitatif . Jakarta: PT Raja Grafindo Persada, 2003

[7] Dewi, N. L. A. D. S., Iga Oka Suryawardani, I Dewa Gede Raka Sarjana. "Strategi Pemasaran Kopi pada Perusahaan Kopi Banyuatis", E-Jurnal Agribisnis dan Agrowisata. Vol.5, No.1., 2015.

[8] Elisha, L.C., "Analisis Ekspor Kopi Indonesia Ke Amerika Serikat Dengan Pendekatan Error Correction Model", Economics Development Analysis Journal. 4 (4), 2015.

[9] Hervinaldy. "Strategi Pemerintah Indonesia dalam Meningkatkan Ekspor Kopi ke Amerika Serikat”. JOM FISIP, 4(2):1-15, 2017.

[10]Purnamasari, M., Nuhfil Hanani, Wen-Chi Huang. "Analisis Daya Saing Ekspor Kopi Indonesia di Pasar Dunia”. AGRISE, Vol. XIV. 2014. 
[11]Putri, D. D., Altri Mulyani, Ratna Satriani. "Strategi Pemasaran Keripik Pisang Dalam Rangka Mencapai Ketahanan Pangan Di Kecamatan Cilongok, Kabupaten Banyumas". Jurnal SEPA : Vol. 8 No.2, 2012.

[12]R Iskandar, Wenny Dhamayanthi, and Ida Adha Anrosana Pongoh. 2018. Quality Improvement of Vannamei Shrimp Production Process Using ISO 9001:2015, IOP Conf.Ser.: Earth Environ. Sci. $207 \quad$ https://doi.org/10.1088/17551315/207/1/012011.

[13]Rangkuti. F.. Analisis SWOT Teknik Membedah Kasus Bisnis, Cara Perhitungan Bobot, Rating, dan OCAI. Jakarta : Gramedia Pustaka Utama. 2014.

[14]S. Nalurita, Ratna Winandi Asmarantaka dan Siti Jahroh. "Analisis Daya Saing dan Strategi Pengembangan Agribisnis Kopi Indonesia”. Jurnal Agribisnis Indonesia, Vol. 2 No. 1., 2014.

[15]S. L. Thomas. Decision Making For Leaders. University of Pittsburgh, 2000

[16] Sidabalok, S.. "Analisis Faktor-Faktor yang Mempengaruhi Ekspor Komoditas Teh Indonesia". Jurnal Penelitian Pendidikan Sosial Humaniora, Vol. 2 No. 2. 2017.

[17] Sihotang, J.. "Analisis Faktor-Faktor Yang Memengaruhi Ekspor Kopi Indonesia di Pasar Internasional”. Jurnal Ekonomi dan Bisnis Nommensen. Fakultas Ekonomi Universitas HKBP Nommensen Pematang Siantar. 2013.
18] Soviandre, E., Musadieq, M., \&Fanani, D. 2014. "Mempengaruhi Volume Ekspor Kopi Indonesia ke Amerika Serikat". Jurnal Administrasi Bisnis (JAB), Vol. 14 No. 2.

[19]I N. Sugiharta, Dwi Putra Darmawan, I Dewa Ayu Sri Yudhari. "Strategi Pemasaran Benih Padi Pada UD Tani Sejati Kecamatan Blahbatuh Kabupaten Gianyar". E-Jurnal Agribisnis dan Agrowisata. Vol.5, No.4. 2016

[20] Sugiyono. Memahami Penelitian Kualitatif. Bandung: CV. Alfabeta. 2006.

[21] Sundari, S., Ridwan Iskandar and Ernie Tisnawati Sule. The Effect of Implementation Quality System on the Quality Culture of Farmers (Case Study on Edamame Production Industries). Mediterranean Journal of Social Sciences, 6(5):209-215. 2015.

22] Suprayogi, B.M., Zainul Arifin, Mukhammad Kholid Mawardi. Analisis Daya Saing Ekspor Kopi Indonesia, Brazil, Kolombia dan Vietnam. Jurnal Administrasi Bisnis, 50(2):190-194. 2017.

[23] Widayanti, S.. Analisis Ekspor Kopi Indonesia. WACANA, Vol. 12 No.1. 2009 